\title{
Body image perception in relation to recent weight changes and strategies for weight loss in a nationally representative sample in the European Union
}

\author{
Sinead McElhone ${ }^{1}$, John M Kearney ${ }^{1}$, Ismene Giachetti ${ }^{2}$, Hans-Joachim Franz Zunft ${ }^{3}$ and \\ J Alfredo Martínez ${ }^{4}$ \\ ${ }^{1}$ Institute of European Food Studies, Trinity College, Dublin 2, Ireland: ${ }^{2}$ CNERNA-CNRS, 16 rue Claude Bernard, \\ 75005 Paris, France: ${ }^{3}$ German Institute of Human Nutrition, Arthur-Scheunert-Allee 144-166, D-1 4558 Bergholz- \\ Rehbruecke, Germany: ${ }^{4}$ Universidad de Navarra, Departmento Fisiologia y Nutricion, 31008 Pamplona, Spain
}

\begin{abstract}
Objectives: To assess body image perception and satisfaction with current body image across the EU and to explore the influence of sociodemographic variables, body-weight change and strategies for losing weight on body image perception.

Design: A cross-sectional study in which quota-controlled, nationally representative samples of approximately 1000 adults from each country completed a face-to-face interview-assisted questionnaire.

Setting: The survey was conducted in the 15 member states of the EU between March and April 1997.

Subjects: The questionnaire was completed by 15239 subjects (aged 15 years and upwards). Data were weighted by population size for each country and by sex, age and regional distribution within each member state.

Results: Just 39\% of respondents in the EU were satisfied with their weight and these were more likely to be male (46\%) rather than female (31\%). Across the EU $29 \%$ of Finnish subjects were content with their weight compared with $47 \%$ in Belgium and $48 \%$ in Luxembourg. The highest percentage of subjects who were content with their body weight was among females who were underweight (58\%) and males who were normal weight (66\%). A further $20 \%$ of underweight females wished to be lighter compared to only $5 \%$ of males. Diet was the most frequently selected method for losing weight especially among females wishing to be considerably lighter (27\%) while males were as likely to use exercise as diet as a strategy to lose weight.

Conclusions: Geographical and sociodemographical influences on body image perception are evident across the EU. There were clear gender differences in the desire to be thinner with a high proportion of females who were underweight being content to be so.
\end{abstract}

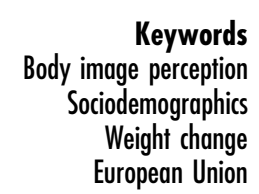

Eating disorders and obesity are both rising in prevalence and are problems of considerable public health significance ${ }^{1}$. Such a trend towards being overweight and obese has also been noted in many developing countries ${ }^{2}$ emphasizing the need for preventive strategies. In attempting to stem the continuing rise in the prevalence of people who are overweight and obese, public health campaigns to increase exercise levels and to reduce caloric intake have been initiated in many countries both at the local and national level ${ }^{3}$. Care must be taken to ensure that in such endeavours to reduce overweight and obese levels a realistic and healthy body weight is the goal of such campaigns ${ }^{4}$. This is particularly important in order to avoid a concomitant increase in weight anxiety and restrained eating with an increase in the number of campaigns aimed at increasing exercise levels and reducing excessive food intake.

Ironically, as the prevalence of being overweight and obese has continued to rise, the cultural ideal of women has become leaner ${ }^{5}$. Such a strong societal emphasis on appearance and thinness has resulted in both an intense body preoccupation ${ }^{6,7}$ and a willingness to try out virtually any weight loss strategy ${ }^{8}$. But while body shape and beauty have been important through the ages, being thin was not always seen as beautiful and desirable. Indeed the concept of what is ideal and desirable in women's beauty has changed a great deal. In the Renaissance period, desirable women were portrayed as large and curvaceous with a body shape indicative of reproductive prowess and an affluent background ${ }^{9}$. Such a shape in today's world 
would be deemed grossly overweight. The move in the last four decades has been progressively towards a thinner and thinner ideal ${ }^{10}$. Aspiring to be thin in order to meet some cosmetic standard or cultural ideal is undesirable as it results in an unhealthy level of weight preoccupation and eating disorders ${ }^{11}$. The aim rather should be to lower the level of morbidity resulting from being overweight and obese and that the goals for weight loss among the obese should be short term ${ }^{11}$.

To get a better understanding of weight concerns and pressures to be slim it is necessary to consider the psychological determinants of body image. These pertain to body focus, attractiveness and self-worth as well as to a pressure to succeed ${ }^{8}$. Indeed two aspects of these, perfectionism and an over-riding achievement orientation are thought to be risk factors rather than protective factors for weight preoccupation ${ }^{12}$. The study of body image in the context of body size (weight) is particularly important in the study and in the understanding of eating disorders such as anorexia nervosa and bulimia nervosa. Bell and co-workers ${ }^{13}$ found that there was a trend for anorexic overestimation and obese underestimation. However, body image inaccuracies should not be a criterion for anorexia nervosa since it is not confined to that population ${ }^{14}$. Body image represents an individual's subjective experience with his or her body and the manner in which he or she organizes this experience ${ }^{15}$. It plays a major role in self-concept, a complex structure that embraces not only the body but also social and personal relationships ${ }^{8}$. The aspect of body image that is most often distorted is size/weight; this may be a consistent exaggeration of the body as a whole or specific parts of the body-typically the hips and waist ${ }^{16,17}$. The relationship of body image to body weight and self-esteem has been studied in relationship to weight anxiety and eating disorders ${ }^{18-20}$. It is thought that sociocultural and psychological factors underlie the intense preoccupation with the body and 'fear of fatness ${ }^{8}$. A question on current and ideal body image was asked in conjunction with other questions on height and weight (self-reported) to get a measure of body mass index (BMI), recent weight changes and strategies for weight loss. This is the first study to examine the association between perceived body image in relation to various demographic characteristics, BMI, weight change and strategies for weight loss in a large nationally representative sample of the EU.

\section{Methods}

A workshop was held in which a project management group designed a questionnaire consisting of 12 questions. The Project Management Group consisted of scientists from each member state, participants from the food industry, along with some experts from the field of obesity and physical activity research. In each member state approximately 1000 adults aged 15 years and upwards were selected, except in Luxembourg where 500 adults were selected, in the UK where 1250 were selected (with 250 coming from Northern Ireland) and in Germany where 1250 were selected. In total a sample of 15239 adults completed a face-to-face interview-assisted questionnaire conducted as part of 'Eurobus', a market research organization offering omnibus research. The sample in each country was quota-controlled to make the sample nationally representative. The questionnaire was translated into the language used in each country and was checked for 'meaning' prior to administration to ensure it had retained its original sense. The survey was conducted between March and April 1997. Details concerning the number of respondents interviewed in each member state, sample selection and questionnaire design are described in detail elsewhere ${ }^{21}$.

Body image was assessed through the use of a silhouette matching technique ${ }^{21}$. A series of illustrations of male and female figures with increasing body weight from figure 1 to figure 9 were used to assess current and ideal body image. These are shown in Fig. 1. Body images 1-3 correspond to underweight $\left(\right.$ BMI $\leqslant 19.99 \mathrm{~kg} \mathrm{~m}^{-2}$ ); body image figures 4 and 5 correspond to normal weight (BMI $20-24.99 \mathrm{~kg} \mathrm{~m}^{-2}$ ); body image figures 6 and 7 correspond to overweight (BMI $25-29.99 \mathrm{~kg} \mathrm{~m}^{-2}$ ) and body image figures 8 and 9 correspond to obese (BMI $\geqslant 30 \mathrm{~kg} \mathrm{~m}^{-2}$ ). These BMI categories are in accordance with the WHO (IOFT) proposals in $1998^{22}$. Subjects were first asked to select which body image figure best depicts their current body weight and then which one best depicts the weight they would like to be (their ideal). In order to examine the relationship between the selection of current and ideal body image further, four groups were identified according to the relationship between perceived, current and ideal body image. These four groups were identified as follows:

1. Heavier: Subjects selected an ideal body image figure which was greater than their current body image figure. This group wish to be heavier than they perceive themselves to be.

2. Content: Subjects selected an ideal body image which matched their perceived current body image. This group are content with their perceived body weight.

3. Lighter: Subjects selected an ideal body image figure which was one figure less than their current body image figure. This group would like to be a bit lighter than they already perceive themselves to be.

4. Considerably lighter: Subjects selected an ideal body 
image figure which was two or more figures less than their perceived current body image figure. This group would like to be considerably lighter than their perceived current body image.

Using these groups we then examined how they were related to sociodemographic factors, BMI (from self-reported height and weight), recent weight changes and strategies for weight loss.

Within each country the samples were weighted for national representativeness as described elsewhere ${ }^{21}$ and the combined EU sample was weighted for population size. Due to the large sample size $(n=15239)$ small differences in the order of $1-2 \%$ for estimates between groups were highly statistically significant $(P<0.0001)$. For this reason, data were analysed by descriptive statistics and the results are given as the percentage of subjects (country or demographic categories) selecting each figure in the question.

\section{Results}

The percentage of subjects in the EU at each level of perceived current body image and ideal body image are shown in Fig. 1. A higher percentage of EU subjects who felt that their ideal matched their current body image selected body image figures below the average
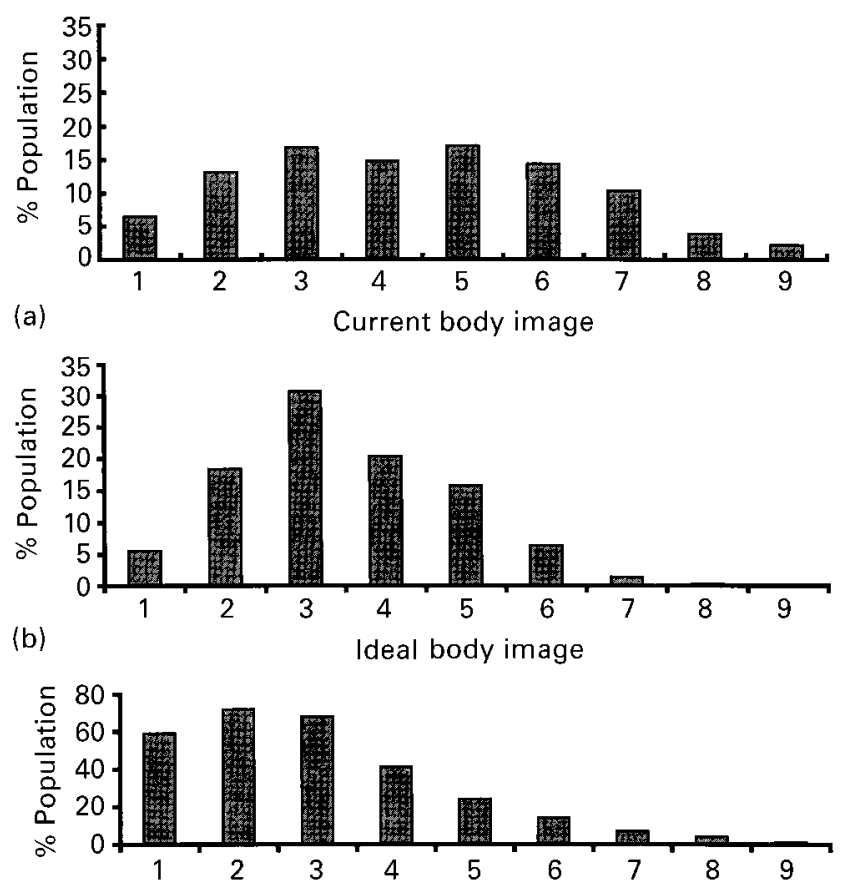

(c)

Ideal matches current body image

Fig. 1 Percentage of subjects in the EU: (a) at each level of current body image; (b) at each level of ideal body image; (c) who feel their ideal body image matches their current body image
Table 1 Percentage of EU males and females selecting current and ideal body image figures $(1-9)$

\begin{tabular}{lrrrrrrrrr}
\hline & \multicolumn{10}{c}{ Body image figures } \\
\cline { 2 - 10 } & 1 & 2 & 3 & 4 & 5 & 6 & 7 & 8 & 9 \\
\hline $\begin{array}{l}\text { Current body image } \\
\quad \text { Male }\end{array}$ & 9 & 18 & 19 & 16 & 15 & 11 & 9 & 2 & 1 \\
$\quad$ Female & 4 & 9 & 15 & 14 & 19 & 18 & 12 & 5 & 3 \\
$\begin{array}{l}\text { Ideal body image } \\
\quad \text { Male }\end{array}$ & 7 & 22 & 30 & 21 & 12 & 5 & 1 & $<1$ & $<1$ \\
$\quad$ Female & 4 & 15 & 31 & 20 & 19 & 8 & 2 & $<1$ & $<1$ \\
\hline
\end{tabular}

BMI or body image figure 4 (Fig. 1c). As many as $60 \%$ of subjects selecting body image figure 1 as their current body weight also selected it as their ideal body image. With increasing perceived current body weight there was a decrease in the percentage of subjects selecting their current body image as their ideal. Only $40 \%$ of EU subjects with a current body image of figure 4 are happy with their weight, implying that the other $60 \%$ are not content with how they perceive themselves to be and aspire to being thinner or heavier.

While for both males and females, body image figure 3 was the most frequently selected ideal body image (Table 1), males were more likely to select body image figures 1 and 2 for their current body image compared with females. The overweight body images (figures 7-9) were selected by more females compared to males. Thus, more males perceive themselves to be thin and more females perceive themselves to be overweight and obese.

Table 2 gives a picture of the cultural differences for the 'thin ideal' by expressing the percentage of subjects selecting underweight body image figures $(1-3)$ as their ideal body weight to the percentage of subjects selecting normal body image figures (4-5) as their ideal body weight as a ratio. This ratio varied

Table 2 Ratio of the percentage of subjects in each member state selecting underweight figures $(1-3)$ to the percentage of subjects selecting normal weight figures (4-5) as their ideal body weight

\begin{tabular}{lrc}
\hline Country & No. & $\begin{array}{r}\text { Selection of underweight figures (1-3) } \\
\text { to normal weight figures }(4-5)\end{array}$ \\
\hline Austria & 931 & 1.56 \\
Belgium & 982 & 1.39 \\
Denmark & 1147 & 1.19 \\
Finland & 979 & 1.22 \\
France & 1003 & 1.94 \\
Germany & 1159 & 1.41 \\
Greece & 1011 & 2.24 \\
Ireland & 1001 & 1.00 \\
Italy & 1000 & 2.06 \\
Luxembourg & 518 & 1.97 \\
Netherlands & 1010 & 1.14 \\
Portugal & 1007 & 1.19 \\
Spain & 1000 & 1.46 \\
Sweden & 1001 & 1.29 \\
UK & 1490 & 1.15 \\
\hline
\end{tabular}


Table 3 Percentage of subjects in each member state classified according to their perceived current : ideal body image relationship

\begin{tabular}{lrcccr}
\hline Country & No. & Heavier & Content & Lighter & $\begin{array}{c}\text { Considerably } \\
\text { lighter }\end{array}$ \\
\hline Austria & 931 & 4 & 39 & 45 & 12 \\
Belgium & 982 & 6 & 47 & 38 & 9 \\
Denmark & 1147 & 8 & 41 & 44 & 7 \\
Finland & 979 & 8 & 29 & 51 & 12 \\
France & 1003 & 8 & 41 & 42 & 9 \\
Germany & 1159 & 6 & 41 & 46 & 8 \\
Greece & 1011 & 7 & 32 & 43 & 18 \\
Ireland & 1001 & 7 & 41 & 42 & 9 \\
Italy & 1000 & 7 & 35 & 49 & 9 \\
Luxembourg & 518 & 5 & 48 & 38 & 10 \\
Netherlands & 1010 & 7 & 38 & 45 & 13 \\
Portugal & 1007 & 9 & 43 & 35 & 12 \\
Spain & 1000 & 8 & 41 & 39 & 11 \\
Sweden & 1001 & 9 & 34 & 43 & 10 \\
UK & 1490 & 9 & 39 & 44 & 44 \\
EU average* & 15239 & 7 & & &
\end{tabular}

*Weighted according to population size.

from as little as 1.00 in Ireland to 2.24 in Greece and 2.06 in Italy. Thus, only in Ireland was there an equal proportion of subjects selecting normal weight body images and underweight body images as their ideal body weight. In all other member states there were more subjects who selected underweight body images than normal weight body images as their ideal body weight.

Just 39\% of subjects in the EU were satisfied with their weight (Table 3), in that these subjects selected the same body image figure as their current and ideal body image. Only $7 \%$ wanted to be heavier, selecting an ideal body image which was greater than their current body image, while the majority of EU subjects wanted to be lighter (54\%). The relationship of ideal to current body image was examined in terms of geographical (Table 3) and demographic characteristics (Table 4) to examine the influence of country and demographic variables (sex, age group and educational level). Finland had the lowest percentage

Table 4 Demographic characteristics of EU subjects classified according to their perceived current : ideal body image relationship

\begin{tabular}{lrrrr}
\hline & Heavier & Content & Lighter & $\begin{array}{c}\text { Considerably } \\
\text { lighter }\end{array}$ \\
\hline Sex & & & & \\
$\quad$ Male & 10 & 46 & 36 & 8 \\
$\quad$ Female & 5 & 31 & 51 & 13 \\
Age group (years) & & & & \\
$\quad$ 15-34 & 11 & 43 & 38 & 8 \\
35-54 & 6 & 35 & 47 & 12 \\
55+ & 5 & 37 & 46 & 12 \\
Education level & & & & \\
$\quad$ Primary & 6 & 37 & 44 & 13 \\
$\quad$ Secondary & 8 & 38 & 44 & 10 \\
$\quad$ Tertiary & 8 & 43 & 42 & 8 \\
\hline
\end{tabular}

of subjects who were content with their body weight (29\%) and the highest percentage of subjects wishing to be lighter (51\%), while in Belgium and Luxembourg almost half of the sample were content with their body weight. Among those wishing to be considerably lighter, Greece had the highest percentage of subjects (18\%) while Denmark had the lowest (7\%).

The largest demographic differences were seen between males and females (Table 4). Twice as many males wanted to be heavier (10\%) compared with females (5\%). Considerably more males (46\%) were also content with their body weight compared with females (31\%). Conversely, a far higher proportion of females wished to be lighter or considerably lighter compared with males. Some differences were also observed across age groups, with more subjects in the youngest age group wishing either to be heavier or content with their weight compared with the older age groups. Within the youngest age group, almost twothirds of women selected an ideal body image which was less than their current one compared with less than one-third of males in this age group (results not shown). Education level had a less pronounced effect on the perceived current:ideal body image relationship. Subjects with a primary-level education were less likely to be content with their body weight and were more likely to want to be 'considerably lighter' compared with subjects educated to secondary or tertiary level.

A strong relationship exists in both men and women between BMI (calculated from self-reported height and weight) and body image (Table 5). The highest percentage of subjects who were content with their body weight was among females who were underweight $(58 \%)$ and males who were normal weight (66\%). A further $20 \%$ of underweight females wished 
Table 5 Percentage of EU males and females in each current : ideal body image category classified by BMI category

\begin{tabular}{|c|c|c|c|c|c|c|c|c|}
\hline \multirow[b]{2}{*}{$\begin{array}{l}\text { Current : ideal body } \\
\text { image category }\end{array}$} & \multicolumn{2}{|c|}{ Underweight } & \multicolumn{2}{|c|}{ Normal weight } & \multicolumn{2}{|c|}{ Overweight } & \multicolumn{2}{|c|}{ Obese } \\
\hline & $\begin{array}{c}\text { Male } \\
(n=425)\end{array}$ & $\begin{array}{c}\text { Female } \\
(n=1224)\end{array}$ & $\begin{array}{c}\text { Male } \\
(n=3465)\end{array}$ & $\begin{array}{c}\text { Female } \\
(n=3886)\end{array}$ & $\begin{array}{c}\text { Male } \\
(n=2580)\end{array}$ & $\begin{array}{c}\text { Female } \\
(n=2019)\end{array}$ & $\begin{array}{c}\text { Male } \\
(n=628)\end{array}$ & $\begin{array}{l}\text { Female } \\
(n=778)\end{array}$ \\
\hline Heavier & 49 & 22 & 13 & 3 & 2 & 1 & - & 1 \\
\hline Content & 46 & 58 & 66 & 37 & 29 & 14 & 10 & 5 \\
\hline Lighter & 5 & 20 & 20 & 53 & 58 & 66 & 54 & 50 \\
\hline Considerably lighter & - & - & 2 & 6 & 11 & 19 & 36 & 44 \\
\hline
\end{tabular}

Table 6 Percentage of EU men and women who have gained, lost or stayed the same weight in the last 6 months classified by their perceived current : ideal body image relationship

\begin{tabular}{|c|c|c|c|c|c|c|c|c|}
\hline \multirow[b]{2}{*}{ Weight change } & \multicolumn{2}{|c|}{ Heavier } & \multicolumn{2}{|c|}{ Content } & \multicolumn{2}{|c|}{ Lighter } & \multicolumn{2}{|c|}{ Considerably lighter } \\
\hline & $\begin{array}{c}\text { Male } \\
(n=726)\end{array}$ & $\begin{array}{c}\text { Female } \\
(n=400)\end{array}$ & $\begin{array}{c}\text { Male } \\
(n=3286)\end{array}$ & $\begin{array}{c}\text { Female } \\
(n=2577)\end{array}$ & $\begin{array}{c}\text { Male } \\
(n=2520)\end{array}$ & $\begin{array}{c}\text { Female } \\
(n=4051)\end{array}$ & $\begin{array}{c}\text { Male } \\
(n=623)\end{array}$ & $\begin{array}{c}\text { Female } \\
(n=1049)\end{array}$ \\
\hline Gained & 16 & 10 & 10 & 13 & 28 & 31 & 34 & 36 \\
\hline Lost weight & 17 & 34 & 10 & 14 & 14 & 18 & 18 & 20 \\
\hline Stayed the same & 65 & 51 & 79 & 71 & 56 & 51 & 46 & 42 \\
\hline Do not know & 2 & 5 & 1 & 2 & 2 & - & 2 & 2 \\
\hline
\end{tabular}

Table 7 Methods used by EU men and women trying to lose weight classified by their perceived current: ideal body image relationship (\%)

\begin{tabular}{|c|c|c|c|c|c|c|c|c|}
\hline \multirow[b]{2}{*}{ Weight loss method } & \multicolumn{2}{|c|}{ Heavier } & \multicolumn{2}{|c|}{ Content } & \multicolumn{2}{|c|}{ Lighter } & \multicolumn{2}{|c|}{ Considerably lighter } \\
\hline & $\begin{array}{c}\text { Male } \\
(n=726)\end{array}$ & $\begin{array}{c}\text { Female } \\
(n=400)\end{array}$ & $\begin{array}{c}\text { Male } \\
(n=3286)\end{array}$ & $\begin{array}{c}\text { Female } \\
(n=2577)\end{array}$ & $\begin{array}{c}\text { Male } \\
(n=2520)\end{array}$ & $\begin{array}{c}\text { Female } \\
(n=4051)\end{array}$ & $\begin{array}{c}\text { Male } \\
(n=623)\end{array}$ & $\begin{array}{c}\text { Female } \\
(n=1049)\end{array}$ \\
\hline Diet & - & 3 & 2 & 5 & 11 & 17 & 16 & 27 \\
\hline Exercise & - & 1 & 3 & 3 & 11 & 10 & 12 & 8 \\
\hline Diet and exercise & 1 & 1 & 2 & 1 & 8 & 10 & 9 & 12 \\
\hline Medication & - & - & - & - & - & 1 & - & 1 \\
\hline Other methods & - & - & 1 & 2 & 4 & 7 & 5 & 7 \\
\hline Total & 1 & 5 & 8 & 11 & 34 & 45 & 42 & 55 \\
\hline
\end{tabular}

to be lighter compared with only $5 \%$ of males who were underweight. Those wishing to be 'considerably lighter' rose with increasing BMI among both males and females, though this rise was higher among females (Table 5).

Recent weight changes among EU men and women according to category of perceived current : ideal body image relationship were also examined (Table 6). Among those in the 'content' category, 79\% of men and $71 \%$ of women stayed the same weight. This was considerably more than those who wish to be lighter, of whom just over half (56\% of men and 51\% of women) stayed the same weight, and those wishing to be a lot lighter, with only $46 \%$ of males and $42 \%$ of females not changing their weight in the last 6 months. The highest percentage of subjects to gain weight in the last 6 months was among women who wished to be a lot lighter (36\%). In contrast, the highest percentage of subjects to lose weight (34\%) was among women wishing to be heavier.

The various methods used by those trying to lose weight among EU males and females was classified according to perceived current:ideal body image relationships (Table 7). Predictably, the percentage of subjects trying to lose weight increases sharply among those wishing to be lighter or considerably lighter with as many as 55\% of females who wish to be considerably lighter trying to lose weight. Diet was the most frequently selected method for losing weight, especially among females wishing to be considerably lighter (27\%). While males were as likely to use exercise as a method of weight loss across all groups of body weight satisfaction, females were more likely to use diet than exercise especially among those who wish to be considerably lighter, where there was a three-fold difference between the use of diet and exercise to lose weight.

\section{Discussion}

There are a number of methods used for assessing body image including verbal descriptions, mirror imaging $^{23}$ and silhouette matching techniques ${ }^{24-26}$. For a large sample size in a face-to-face interviewassisted survey, the silhouette matching technique is considered to be the most appropriate. With this 
technique subjects are shown a series of silhouettes of female or male shapes and asked which one best depicts their own body weight/shape ${ }^{24}$. In this study respondents were asked first which figure best matches their current body weight and then which one best matches their ideal body weight. Such a technique involving figures rather than verbal descriptors was desirable in this survey as it overcame the language difficulties that might arise in distinguishing between the different body weights. Following translation into many languages, descriptive terms for body image are more subject to variable interpretation. The choice of figures for this study was based on those most often used in European studies ${ }^{22}$ compared with others which have been used more frequently in US studies $^{24,25}$.

Numerous studies on body image have shown that women are more likely than men to perceive themselves as overweight and to express dissatisfaction with their body shape $\mathrm{f}^{17,19,26-28}$. These findings were confirmed in the present study. A strong gender difference exists in the percentage of EU subjects who are content with their body weight - with $46 \%$ of males compared with $31 \%$ of females content with their current body weight. Fallon and Rozin ${ }^{17}$ compared current and ideal figures in a sample of 469 college students from the northeastern section of the United States to explore dissatisfaction with current appearance and found that $32 \%$ of men rated their current figure as heavier than their ideal in comparison to about $70 \%$ of the women. They propose that such gender differences are probably related to the greater incidence of weighing, dieting, anorexia and bulimia among American women than among American men. Drewnowski and Yee $^{27}$ found that in their sample of college male and female freshmen, while $85 \%$ of 18 -year-old women wanted to lose weight, men were equally split between those who wanted to gain weight and those who wanted to lose it. The societal pressure to be thin is particularly intense for women. Indeed, marked gender differences in messages conveyed by the mass media have been noted by Czajka-Narins and Parham ${ }^{29}$. In another study, sex and generation differences were examined with respect to concern about weight ${ }^{30}$. This study concluded that sex was considerably more important than generation differences with the implication that the importance of weight, rather than disparity from the ideal, is a fundamental factor in understanding attitudes to weight and perhaps the origins of eating disorders. In a study on a sample of US college students it was found that women who had poor body images and who desired to lose weight were more likely to report eating difficulties ${ }^{28}$. It is possible that the greater dissatisfaction with current body weight among women and the greater pressure to be thin is due in part to women perceiving that men will find a thin ideal as the most attractive $^{30}$. In a study involving college students, women were asked to select the female figure they felt would be ideal for men, while men had to select the male figure they believed to be ideal for women. Women perceived that men will desire a thinner ideal than they actually do, while males perceived that females will desire a heavier body size than they actually do. Another factor, which may explain the gender differences in perceived body image is in the fundamentally different ways that men and women view their bodies ${ }^{8}$. While men see their bodies more in terms of its function and active role, women view it more among aesthetic dimensions ${ }^{31}$.

Satisfaction with body weight varied with age, with the youngest age group being twice as likely to want to be heavier and more likely to be content with their weight (picking an ideal body image which was heavier than their current body image) compared with the two older age groups. Some of these agerelated differences in satisfaction with body weight may be a reflection of their actual body weight. There are more underweight people (BMI $\leqslant 19.99$ ) in the youngest age group compared with the other age groups which have more overweight and obese subjects. In a study involving adolescents, the desire to be heavier than at present was strongest among boys $^{32}$. They wanted to be bigger or heavier than they were as they felt it would be desirable to be more 'muscular'.

The higher percentage of subjects with a primarylevel education wishing to be considerably lighter compared with those with a higher education level may be more of a reflection of their relatively higher BMI than any particular social pressure to be thin in this group. Eating disorders have been found to be more common among those that are most involved in dieting and weight loss and these are predominantly white upper class young females ${ }^{20}$.

An overall correlation appears to exist between cultural pressure to be thin and prevalence of eating disorders both across and within different ethnic groups $^{33}$. In the present study, intercountry comparisons were made into the perceptions of body image to describe the influence of geography and culture on satisfaction with body weight and ideal body image. This was the first study to look at perceived body image across all member states of the EU. Most other studies on body image have been carried out on US subjects. In almost all member states, the percentage of subjects selecting a thin body image as their ideal exceeded (sometimes by a factor of 2 ) the percentage selecting a normal body-weight range. This choice of a 'thin' ideal body weight was highest in Greece, Italy and France. Interestingly, this did not correlate with the proportion of subjects in these countries who were 
thin. For example, while France had the highest percentage of underweight subjects (17\%), Greece had a much lower prevalence at 9\%. Only in Ireland did the thin ideal match with an ideal in the normal weight range. In spite of the large and distinct cultural differences that exist between countries in the EU the differences in those wishing to be thinner, content or heavier were not that large. This was similar to the findings for BMI categories across member states ${ }^{34}$ where differences were generally small. Finland had the lowest percentage of subjects who were content with their weight. This may reflect the numerous national campaigns held in that country aimed at reducing weight through increased exercise and a low-fat diet.

While satisfaction with one's body weight (where ideal body image matches current body image) declines with increasing BMI the decline is more marked in women, falling from 58\% of underweight women to $5 \%$ among obese women. Perhaps, more interesting was the fact that while there were more men of normal weight who were content with their weight (66\%) compared with underweight men (46\%) the opposite was true among women, with 58\% of women who were underweight content to be such compared with just $37 \%$ of normal weight women. Such results lend strong evidence to the societal and cultural pressure among women to be thin. Only just over one-third of normal weight women (compared with two-thirds of normal weight men) in the EU are content with their body weight. Thus, in spite of being within the normal weight range they desire to be thinner. This concurs with a number of previous studies on American subjects ${ }^{35,36}$. It also agrees with the conclusions reached by Wooley and Wooley ${ }^{37}$ on a survey conducted by Glamour magazine on 33000 women: 'that no woman, no matter what size she is feels thin enough'. Furthermore, they found that the greater the level of dissatisfaction with body size the more likely undesirable methods of weight loss were to be used $^{37}$. The results from the pan-EU study lend further support to the need to emphasize a healthy and realistic body weight in any campaign aimed at encouraging weight loss, especially among women who are in the normal or underweight range.

The highest percentage of EU subjects staying the same weight over the last 6 months was found amongst those men (79\%) and women (71\%) who were 'content' with their body weight. Women with stable weight have been found to have the highest self-esteem and to be more satisfied with their body image ${ }^{38,39}$. Indeed, results from the study by Foreyt and colleagues ${ }^{39}$ suggest that weight fluctuation is strongly associated with negative psychological attributes in both normal and obese individuals. Among those women who wanted to be heavier over one-third of them actually lost weight while only $10 \%$ gained weight. It may be that this group of women generally have difficulty putting on weight and this is reflected in the low proportion actually gaining weight in spite of the desire to do so. The reverse occurred among women and men wishing to be 'lighter' or 'considerably lighter' with almost twice as many gaining weight in the last 6 months compared with those who lost weight. Perhaps the desire to be lighter or a lot lighter is a direct response to the fact that they have recently gained weight.

In spite of being content with their body weight $11 \%$ of women and $8 \%$ of men in the EU have been trying to lose weight in the last 6 months. This increases to $55 \%$ of women and $42 \%$ of men who would like to be considerably lighter. The relative proportion choosing dieting as the strategy for losing weight compared with other methods is highest among the group wishing to be considerably lighter, especially among females. While men were equally likely to select exercise or dieting as a means of body weight control, women were more inclined to select diet than exercise. This is similar to the findings from a study by Drewnowski and $\mathrm{Yee}^{27}$ on 226 male and female freshmen students. Men used exercise for weight control while women used restricted calorie diets. This difference in behaviour related to diet and exercise rather than a dissatisfaction with body weight may be the key difference between the sexes with respect to eating disorders ${ }^{27}$. With less females being content with their current body weight than males it is perhaps not surprising to find more of them trying to lose weight. But what is interesting is the fact that this applies irrespective of satisfaction with current body weight, so that even among those who wish to be heavier or are content with their body weight more women are trying to lose weight compared with men. In one American report, women exceeded men by a ratio of $4: 1$ in commercial weight loss programmes ${ }^{40}$. This is in spite of the fact that the medical consequences of being overweight are believed to be more significant for men ${ }^{9}$. The proportion of EU subjects trying to lose weight by dieting or exercise is not dissimilar to US data. As many as half of all American women and a fourth of all American men have dieted at one time or another $^{29}$ and at any one time $15-35 \%$ of Americans are trying to lose weight. Results from this pan-EU survey indicate that more women than men are dissatisfied with their body weight and, in spite of being in the normal BMI range, more of them are trying to lose weight than men, which may help to explain the greater incidence of eating disorders among women. Hesse-Biber et al. ${ }^{28}$ noted that the effects of body image and desired weight change on eating disorders were generally found to be greater for women than men and that women who had poor body 
images and who desired to lose weight were more likely to report eating difficulties. Furthermore, a key risk factor for eating disorders may be dieting itself ${ }^{41}$.

There are some who caution against the use of population-based weight loss campaigns until such time as better data about the risks of being overweight and the benefits and risks of trying to lose weight become available ${ }^{42}$. This is in light of the fact that in many instances the cure for obesity may be worse than the condition itself. One cannot underestimate the effects of guilt and self-hatred which come as a consequence of failed attempts at losing weight, not to mention the enormous financial losses because so many people cannot lose weight, no matter how hard they try ${ }^{43}$. Such sentiments lend further weight to the argument that the best public health approach to the epidemic of obesity is to concentrate on measures to prevent obesity. At the same time, however, gaining an understanding of the issues related to extreme preoccupation and dissatisfaction with body image is essential for developing appropriate recommendations for weight control and maintenance. The findings in this study in terms of the demographic and sociocultural influences on perceived body image in the 15 member states of the EU should be of some help in this regard. Further studies are needed to determine what psychological, sociocultural and demographic factors might explain the differences between men and women of comparable weight and body fatness in their desire to lose weight.

\section{References}

1 Battle EK, Brownell KD. Confronting a rising tide of eating disorders and obesity; treatment vs. prevention and policy. Addict. Behav. 1996; 21: 755-65.

2 Wolk A, Rossner S. Effects of smoking and physical activity on body weight: developments in Sweden between 1986 and 1989. J. Intern. Med. 1995; 237: 287-91.

3 Van Mechelen W. National policies for promoting physical activity, physical fitness and better nutrition in Europe. In: Simpoulos AP, ed. Nutrition and fitness: evolutionary aspects. Children's health program and policies. World Rev. Nutr. Diet 1997; 81: 136-47.

4 Dwyer JT, Feldman JJ, Seltzer CC, Mayer J. Body image in adolescence: attitudes towards weight and perception of appearance. Am. J. Clin. Nutr. 1996; 20: 1045-56.

5 Metropolitan Life Insurance Company. Statistical Bulletin 1983; 64: 2 .

6 Ryan YM, Gibney MJ, Flynn MAT. The pursuit of thiness: a study of Dublin schoolgirls aged 15 years. Int.J. Obes. 1998; 22: $485-7$.

7 Rodin J, Silverstein L, Streigel-Moore R. Women and weight: a normative discontent. In: Sonderegger TB ed. Psychology and Gender: Nebraska Symposium on Motivation. Lincoln: University of Nebraska Press, 1985; 267-307.

8 Rodin J. Cultural and psychosocial determinants of weight concerns. Ann. Intern. Med. 1993, 119: 643-5.

9 Foster GD, Wadden TA. The psychology of obesity, weight loss and weight regain: research and clinical findings. In:
Wadden TA, Van Italia TB, eds. Treatment of the Seriously Obese Patient. New York: Guilford Press, 1992; 140-66.

10 Fallon A. Culture in the mirror: sociocultural determinants of body-image. In: Cash TF, Pruzinsky T, eds. Body Images: Development, Deviance and Change. New York: Guilford Press, 1990.

11 Rosenbaum M, Leibel RL, Hirsch J. Obesity. N. Engl. J. Med. 1997; 337: 396-407.

12 Striegel-Moore RH, Silberstein LR, Rodin J. Towards an understanding of risk factors for bulimia. Am. Psychol. 1986; 41: 246-63.

13 Bell C, Kirkpatrick SW, Rinn RC. Body image of anorexic, obese and normal females. J. Psychol. 1986; 42: 43-9.

14 Hsu LKC. Is there a disturbance of body image in anorexia nervosa? J. Nerv. Ment. Dis. 1982; 170: 305-7.

15 Fisher S. Development and Structure of the Body-Image, Vol. 1. Hillsdale, NJ: Lawrence Erlbaum, 1976; 169-71.

16 Casper RC, Halmi KA, Goldberg BC, Davis JM. Disturbances in body image estimation as related to their characteristics and outcome of anorexia nervosa. Br. J. Psych. 1979; 134: 60-6.

17 Fallon AE, Rozin P. Sex differences in perception of desirable body shape. J. Abnorm. Psychol. 1985; 94: 102-5.

18 Gila A, Castro J, Toro J, Salamero M. Subjective body-image dimensions in normal and anorexic adolescents. Br. J. Med. Psychol. 1998; 71: 175-84.

19 Halmi KA, Falk JR, Schwartz E. Binge-eating and vomiting. A survey of a college population. Medicine 1981; 11: 697-706.

20 Wilson GT. Relation of dieting and voluntary weight loss to psychological functioning and binge eating. Ann. Intern. Med. 1993; 119: 727-30.

21 Kearney JM, Kearney MJ, McElhone S, Gibney MJ. Methods used to conduct the pan-European Union survey on consumer attitudes to physical activity, body weight and health. Public Health Nutr. 1999; 2: 79-86.

22 Ernaebrungsbericht. Frankfurt: Deutsche Gesellschaft fuer Ernaehrung, 1992; 190-93.

23 Goldsmith D, Thompson JK. The effect of mirror confrontation and size estimation feedback on perceptional inaccuracy in normal females who over-estimate body size. Int. J. Eat. Disord. 1989; 8: 437-44.

24 Williamson DA, Kelly ML, Davis CJ, Ruggiero L, Blouin DC. Psychopathology of eating disorders: a controlled comparison of bulimic, obese and normal subjects. J. Consult. Clin. Psychol. 1985; 53: 161-6.

25 Stunkard AJ, Sorenson T, Schlusinger F. Use of the Danish adoption register for the study of obesity and thinness. In: Kety S, ed. The Genetics of Neurologial and Psychiatric Disorders. New York: Raven Press, 1980; 115-20.

26 Mintz LB, Betz NE. Sex differences in the nature, realism and correlates of body image. Sex Roles 1986; 15: 185-95.

27 Drewnowski A, Yee DK. Men and body image: are males satisfied with their body weight? Psychosom. Med. 1987; 49: 626-34.

28 Hesse-Biber S, Clayton-Matthens A, Downey JA. The differential importance of weight and body image among college men and women. Genet. Soc. Gen. Psychol. Monogr. 1987; 113: 509-28.

29 Czajka-Narins DM, Parham ES. Fear of fat: attitudes towards obesity. The thinning of America. Nutr. Today 1990; January/February: 26-32.

30 Rozin P, Fallon A. Body image, attitudes to weight, and misperceptions of figure preferences of the opposite sex: a comparison of men and women in two generations. J. Abnorm. Psychol. 1988; 97: 342-5.

31 Franzoi SL, Shield SA. The body esteem scale; multidimensional structure and sex differences in a college population. J. Pers. Assess. 1984; 48: 173-8.

32 Wadden TA, Brown G, Foster DG, Letizia KA, Stunkard AJ. 
Salience of weight related worries in adolescent males and females. Int. J. Eat. Disord. 1991; 10: 407-12.

33 Hsu LG. Eating Disorders. New York: Guilford Press, 1990.

34 Martínez JA, Kearney JM, Kafatos A, Paquet S, MartínezGonzález MA. Variables independently associated with selfreported obesity in the European Union. Public Health Nutr. 1999; 2: 125-133.

35 Schulken ED, Pinciaro PJ, Sawyer RG, Jensen J, Hoban MT. Sorority women's body size perceptions and their weightrelated attitudes and behaviours. J. Am. Coll. Health 1997; 46: 69-74.

36 Epel ES, Spanakos A, Kasl-Godley J, Brownell KD. Body shape ideals across gender, sexual orientation, socioeconomic status, race and age in personal advertisements. Int. J. Eat. Disord. 1996; 19: 265-73.

37 Wooley SC, Wooley OW. Feeling fat in a thin society. Glamour 1984; Feb: 198-252.
38 McAllister R, Caltabiano ML. Self-esteem, body-image and weight in non-eating disordered women. Psychol. Rep. 1994; 75: 1339-43.

39 Foreyt JP, Brunner RL, Goodrick GK, Cutter G, Brownell KD, Stjeor ST. Psychological correlates of weight fluctation. Int.J. Eat. Disord. 1995; 17: 263-75.

40 Wadden TA, Foster GD, Letizia KA, Stunkard AJ. A multicentre evaluation of a proprietary weight reduction programme for the treatment of marked obesity. Arch. Int. Med. 1992; 152: 961-6.

41 Polivy J, Herman CP. Dieting and binging: a causal analysis. Am. Psychol. 1985; 40: 193-201.

42 Kassirer JP, Angell M. Losing weight-an ill-fated new year's resolution. N. Engl. J. Med. 1998; 338: 52-4.

43 Rippe JM. Over-weight and health: communication challenges and opportunities. Am. J. Clin. Nutr. 1996; 63 (Suppl.): S470-3. 